\title{
O habitante paisagista ${ }^{(1)}$
}

\author{
SCHIRLEY FATIMA NOGUEIRA DA SILVA CAVALCANTE ALVES E PATRÍCIA DUARTE DE OLIVEIRA PAIVA.(2)
}

\begin{abstract}
RESUMO
Habitante paisagista foi um conceito elaborado por Bernard Lassus, paisagista, professor e pesquisador renomado na área de jardins e paisagens. Participou da retomada da pesquisa da paisagem na França que contou com grande repercussão política, social e econômica na década de 1990, e hoje é uma grande referencia na Europa. Nesse período foi consultor do governo Francês nos assuntos que envolviam questões realacionadas com Parques, Jardins e Paisagens. Nesse último domínio, inovou com sua visão paisagística voltada para as autoestradas e ajudou a sensibilizar o poder público da importância de se investir nas paisagens, apoiando as pesquisas, estimulando novas intervenções e desenvolvendo a atuação dos profissionais da área do paisagismo. Como o ponto de partida da pesquisa de Bernard Lassus se concretizou com a criação do conceito do Habitante Paisagista. Nota-se que o mesmo foi essencial na sua trajetória conceitual e profissional, pois esse conceito foi o elemento revelador da presença do imaginário nesse domínio. Os conceitos desenvolvidos a partir do habitante paisagista foram fundamentais no desenvolvimento do paisagismo na França, abarcando a idéia da presença do imaginário nos projetos de paisagismo e estendendo às paisagens a importância da subjetividade. Quarenta anos depois da criação do conceito do Habitante Paisagista, a criação da Convenção Européia da Paisagem formaliza a importância da participação dos habitantes nos processos de intervenções das paisagens, chamando a atenção para a importância dessa dimensão paisagística em todos os setores de intervenção do espaço. Essa nova visão da paisagem na Europa vem democratizando a profissão do paisagista com o intuito de melhorar o quadro de vida da população.

Durante certo período da história, essa população não foi considerada, e com isso mostrou suas necessidades por meio do imaginário de seus jardins, fato apreendido por Bernard Lassus.
\end{abstract}

Palavras-chave: jardins, paisagem, política da paisagem.

\begin{abstract}
ABSTRAT
Inhabitant landscaper

Inhabitant landscaper was a concept developed by Bernard Lassus, renowned landscaper, professor and researcher in the area of gardens and landscapes. Participated in the resumption of the research landscape in France that featured great political, social and economic repercussion in the 1990s, and today is a great reference in Europe. During that period he was a consultant to the French government in matters involving issues related to Parks, Gardens and Landscapes. In the latter area, innovated with his landscape view facing the motorways and helped raise awareness of the public power the importance of investing in landscapes, supporting research, stimulating new interventions and developing the work of professionals in the landscaping. As the starting point of the research of Bernard Lassus materialized with the creation of the concept of Inhabitant Landscaper. It is noted that it was crucial to his conceptual and professional trajectory, because this concept was the element showing the presence of the imaginary in this area. The concepts developed based on the inhabitant landscaper were crucial in the development of landscaping in France, embracing the idea of the presence of the imaginary in landscaping projects and extending to landscapes the importance of subjectivity. Forty years after the creation of the Inhabitant Landscape concept, the creation of the European Landscape Convention formalizes the importance of participation of people in the processes of interventions in the landscape, drawing attention to the importance of this dimension landscape in all sectors of intervention of space. This new vision of landscape in Europe is democratizing the lanscaper's profession in order to improve the living environment of the population. Along a certain period of history, the population was not considered, and thus showed their needs through the imagination of its gardens, a fact seized by Bernard Lassus.
\end{abstract}

Keywords: gardens, landscape, landscape politic.

\section{INTRODUÇ̃̃O}

Habitante paisagista foi um conceito criado por Bernard Lassus, francês, formado em belas artes e diplomado como paisagista. A teoria criada, exercida e difundida por Bernard Lassus, teve como ponto de partida na década de 1960, quando ele chamou a atenção para a arte dos jardins nas habitações populares francesas e criou a teoria dos habitantes paisagistas. Desde então Lassus começou essa pesquisa, que nunca deixou de dar atenção a esses jardins imaginários, abrindo uma nova perspectiva demo-etnoantropológica no campo da paisagem, fundamentada no incomensurável.

Lassus com sua teoria desenvolveu uma prática que contou com um planejamento cuidadoso dos lugares, sempre enquadrando o que acontecia entre a realidade e a aparência, expondo em todos os seus projetos uma notória clareza. Fertilizado com novas experiências visuais e táteis, enriquecidos pelo encontro de um tipo de paisagem vernacular e seus atores, os habitantes paisagistas, Bernard

\footnotetext{
(1) Recebido em 10 de maio de 2013 e aceito para publicação em 30 junho de 2013.

(2) Universidade Federal de Lavras, Departamento de Agricultura, NEPAFLOR, lavras - MG. sfnsca@terra.com.br, Professora, Dra., Departamento de Agricultura/dag, ufla patriciapaiva@dag.ufl a.br
} 
Lassus elaborou ainda mais estes conceitos, criando com isso sua concepção de projeto paisagístico.

A política da paisagem desenvolvida na França se estendeu à Europa, e em 20 de outubro de 2000, foi assinada em Florença a Convenção Européia da Paisagem, que suscitou grande interesse entre os países membros do Conselho da Europa. A partir de então se desenvolveu uma política na Europa que não se restringiu às paisagens espetaculares, mas também às pitorescas e banais. Com isso tornou-se necessário considerar essas paisagens em todas as ações de gestão, desde as mais amplas até aquelas mais pontuais, ações essas tanto de organização do território, quanto de planejamento e de desenvolvimento regional, especialmente quando estes têm um impacto sobre a qualidade de vida dos habitantes que estão envolvidos.

Entender essa identidade das paisagens comuns é um primeiro passo para um melhor conhecimento desses territórios, sendo um pré-requisito para a elaboração e a implantação de projetos e de implementação de uma política democrática da paisagem, que deve ser direcionada para o conhecimento local e a participação de seus habitantes.

Lassus participou de um grande movimento democrático na França e na Europa para a evolução da paisagem tanto no seu campo de ciências teóricas como aplicadas, contribuindo para com o desenvolvimento da aplicação da dimensão da paisagem, não somente nos jardins, mas nos mais variados campos de intervenção do espaço.

\section{Bernard Lassus}

Bernard Lassus criou o conceito do habitante paisagista. Francês, formado em belas artes pela l'École Nationale Supérieure des Beaux-Arts e diplomado como paisagista pelo Ministério da Agricultura francês.

Como artista plástico, participou de exposições na França, Brasil, Itália e Alemanha, e recebeu diversas homenagens nesse país. Como paisagista recebeu prêmios como o Lauréat na época da implantação do "Jardin de l'Antérieur" na cidade Isle-d'Abeau e do Concurso do Parc de la Corderie Royale de Rochefort-sur-Mer, que fez parte dos grandes trabalhos do presidente da República na década de 1980. Foi consultor nas ultimas intervenções do Jardim das Tulherias e do Parque em Duisburgo.

Nas décadas de 1980 e 1990 foi professor e diretor do D.E.A., "Jardins, Paysages, Territoires" das duas Instituições l'École d'Architecture de Paris-La Villette e l'Ecole des Hautes Etudes en Sciences Sociales, em Paris, na França, onde junto com o grupo dos cinco, retomou a discussão sobre o conceito de paisagem na França, colocando-a em pauta nas formulações de leis e nas discussões políticas da época.

Na década de 1960, participou da fundação da l'École Nationale Supérieure du Paysage de Versailles, e foi professor colaborador da Universidade da Pensilvania, nos Estados Unidos. É preciso ressaltar que ele foi um grande colaborador do desenvolvimento da atuação dos profissionais ligados à paisagem na França, e ainda hoje suas idéias e conceitos são uma referencia na Europa e no mundo.

Inovou o campo de ação dos paisagistas com seus trabalhos nas autoestradas, recebendo também o Ruban d'Or da Direction des Routes du Ministère de l'Equipement.
Como conselheiro de Paisagens junto à Direção das Estradas do governo francês, colaborou com a criação da lei $1 \%$ paisagem, cuja função é designar parte do orçamento da construção das estradas aos projetos paisagísticos.

Para Paquot (2013) Bernard Lassus é um colorista de formação e se apresenta como um paisagista conceitual, se referindo aos seus conceitos da analise inventiva, o inflexus e o heterogeneo, que contribuem às logicas sensiveis, que centram a concepção de seus projetos, nos quais tanto as cores quanto os cinco sentidos são sempre mobilizados adequadamente.

Toda essa teoria criada, exercida e difundida por Bernard Lassus, teve como ponto de partida suas pesquisas para a Délégation Générale à la Recherche Scientifique et Technique na década de 1960, quando ele chamou a atenção para a arte dos jardins na habitações populares francesas e os habitantes paisagistas.

\section{Habitante paisagista}

Segundo Lasus (1999) a denominação de habitante paisagista caracterisa a ação dos habitantes que para realizarem seus jardins, dão uma maior importancia à elaboração de relações, portanto paisagens, do que relação entre os objetos. São jardineiros que com seus pneus usados, montam poços, ou criam seres de gesso e colocam sobre a grama, criando assim um mundo a parte (PAQUOT, 2010).

Bernard Lassus descreve que em 1961, durante um estudo sobre as cores de uma pequena cidade na Corsa, ao se deparar com um animal fantástico, talvez um dragão de cimento verde com longos dentes brancos, e de uma serpente amarela manchada de verde com a língua de metal, ele notou que os habitantes dessa região além de interferirem na paisagem com o colorido de suas casas, eles não se limitavam a organizarem seus espaços externos com as superficcies vegetais e suas circulações pontuadas de elementos florais, eles desenvolviam temas. Nos anos que se sucederam Lassus foi se deparando com vários desses tipos de intervenções, na sua maioria mais modestas, como moinhos, pneus cortados, anõesinhos espalhados nos jardins, e constatou que sobretudo nos conjuntos habitacionais populares esses tipos de decorações se multiplicavam. Lasus então concluiu que com esses tipos de intervenções desses habitantes contrariavam aquilo que lhes havia sido imposto, e que através de tais práticas, esses habitantes iam contra aquilo que lhes foi imposto, e modificavam estruturas consideradas como prontas para realmente poderem "habitarem" estes espaços projetados sem eles para eles (PAQUOT, 1998).

Segundo Ferriolo (2010) os habitantes paisagistas, inspiradores desconhecidos, estão por trás da obra e da pesquisa de Bernard Lassus, que os dedicou um estudo de mais de quinze anos no subúrbio parisiense, aplicando enquetes que tinham como objetivo compreender os mecanismos plásticos de uma estética popular da paisagem. Assim os habitantes paisagistas orientaram Bernard Lassus na elaboração de uma pratica personalizada de projetos.

Ao ser questinado sobre a sensibilidade da paisagem Bernard Lassus esplanou que na época em que ele lançou essa sua teoria dos habitantes paisagistas apareceram criticas quanto ao fato dos habitantes paisagistas não saberem 
explicar suas criações, o que podeira dar um suporte a conclusão de que não seriam verdadeiras criações. Para Lassus os habitantes paisagistas sabiam fazer paisagem, mas não sabiam explicar, e que seu trabalho sobre os habitantes paisagistas talvez não tenha sido demonstrado o suficiente, mas que o deu a oportunidade de mostrar essa realidade (PAQUOT, 1998).

Para Ferriolo (2010) somente aquele que participa do sonho pode comprender o imaginário vertical que anima o jardim. Desde 1961, ano em que Lassus começou essa pesquisa, seu olhar profundo nunca o deixou abandonar esses jardins imaginários, abrindo uma nova perspectiva demo-etno-antropologica no campo paisagem, fundamentados no icomensurável

\section{Jardim e paisagem}

Segundo Alves e Paiva (2010), os jardins são espaços de experiência sensível que se desenvolveram assentados basicamente no sentido da visão, salpicados nessa trajetória temporal com alguns toques sonoros. Atualmente, os outros sentidos ganharam maior interesse, gerando uma forte apelação sensível, abrangendo conotações poéticas que os instigam e atingem outras dimensões. Para Bernard Lassus, apesar dos conceitos jardim e paisagem, serem tão diferentes e às vezes até mesmo opostos, essa distinção foi se amenisando, se imbricando. Bernard Lassus dizia que estava cada vez mais convencido que o jardim é paisagem ou das paisagens. Um jogo bastante complexo que foi se instalando, no qual o imaginário apreende todo o seu significado. Para Lassus depois que Aldrin pos seus pés na lua, a Terra se tornou um jardim, cruzando essas duas escalas tão diferentes, a do jardim um hortus conclusus em latim e a da paisagem, espaço de terreno que se abrange num lance de vista (PAQUOT, 1998).

Segundo Ferriolo (2009) a teoria da paisagem de Bernard Lassus se desenvolveu da partir de conceitos da visibilidade como luz, cor e aparência, chegando no conceito de jardim como sendo uma perspectiva da paisagem, onde as infraestruturas do mesmo, enraizadas no mais profundo de sua essência se abrem no local dentro dessa evolução rápida da globalisação. A relação entre o objeto e a paisagem é complexa, ambígua e mutuamente destrutiva. O uso generalizado do termo "paisagem" e a busca contínua de sua definição demonstra o quanto é difícil escolher as articulações e as ligações entre os objetos nesse contexto (FERRIOLO, 2009).

No jardim de Bernard Lassus, os jogos de formas, de cores, dos sentidos e das espécies se combinam com os jogos do espírito, achando sempre de froma imaginária um lugar (pays) (PAQUOT, 2010).

A atenção para essas relações é o centro da atenção de uma prática da paisagem fundamentada sobre o rápido olhar que abrange apenas uma parte do espaço concreto da escala visual, onde vários elementos individuais estão em uma unidade visível, muitas vezes aberta à visão de uma forma parcial. A paisagem é então, basicamente, uma hipótese de olhar sobre o nosso entorno. Abrangendo mais o não-visível que o visivel, uma interação contínua entre visto e escondido, entre o real eo imaginário, um jogo de imaginação que leva uma abordagem particular, de uma ferramenta de trabalho cujo objetivo é revelar a paisagem, e não para defini-la (FERRIOLO, 2009).

Lassus foi um dos primeiros profissionais franceses a tratar as autoestradas como paisagem. Considerando essa nova dimensão paisagística do território, ele acreditava que a implantação da rede de autoestradas francesas iriam mostrar um outro país. Lassus mostrou que a autoestrada é comparável a um belvedere, ou seja, um vasto ponto de vista, mas um belvedere móvel, criando um grande debate paisagístico na França em torno do tema das autoestradas, pois elas seriam o lugar de onde as pessoas iriam estar sempre abrangendo esses territórios pela visão por meio de inúmeras janelas panorâmicas. Nessa época ele mostrou também a tendência que existia de associar os termos paisagem e movimento, mas, essa associação se fazia a um movimento repetitivo, que ele demonstrou não ser o da paisagem, pois a paisagem está associada à transformação. Para Lassus, a arte do jardim e a arte da paisagem são artes de transformação.

Segundo Ferriolo (2009), Bernard Lassus desenvolveu uma prática que inclui as paisagens, no verdadeiro sentido de sua previsão em seus instrumentos. Para esse autor, não há prática sem teoria e vice-versa, e Lassus com sua teoria desenvolveu uma prática que contou com um planejamento cuidadoso dos lugares, sempre enquadrando o que acontecia entre a realidade e a aparência, expondo em todos os seus projetos uma notória clareza.

\section{Projeto de paisagem}

Fertilizado com novas experiências visuais e táteis, enriquecidos pelo encontro de um tipo de paisagem vernacular e seus atores, os habitantes paisagistas, Bernard Lassus elaborou ainda mais estes conceitos, criando com isso sua concepção de projeto paisagístico, caracterizado por um caráter estético e altamente ético (FERRIOLO, 2009).

Lassus desenvolveu uma prática de paisagem na qual o lugar e o sujeito criador estão intimamente relacionados, uma abordagem transferível para qualquer realidade, aperfeiçoada ao longo do tempo através da experiência e da reflexão contínua sobre os pricipios de um método. Um processo que não elabora objetos, mas suas relações, dando suporte para compreender e elaborar as paisagens. Sua metodologia cria assim uma estética enraizada nos lugares e fundamentada no imaginário, estética essa que vem a ser a prática da paisagem.

O existente é revelado pela análise inventiva, o esboço do projeto, o ponto de partida para qualquer prática de paisagem. Um bom paisagista deve se informar bem por um levantamento físico multidisciplinar e demo etnoantropológico, auxiliado por vários especialistas, e contar com dados seguros do território. A coleta de informações manifesta assim o existente que está em vias de receber novos componentes, mantendo o potencial de cada lugar. Desta forma, pode-se conhecer um sitio pelo fato do mesmo se aproximar de sua característica - na sua história e em todo seu potencial - para assim poder intervir (LASSUS, 1992).

O projeto paisagístico, muitas vezes associado a uma imagem fixa deve centrar-se na abordagem do planejamento paisagístico como a inflexão de um processo. Os elementos do processo, perpetuados ou revelados pela 
análise inventiva são flexionados pelas diretrizes também sugeridas pela mesma, e os novos elementos se entrelaçam progressivamente em um movimento gradual, que por não ser repetitivo, se torna semelhante à evolução. Esta abordagem paisagística leva à inflexão de um processo, o da evolução ordinaria dos lugares, incluindo a arte da transformação (PAQUOT, 1998).

A atenção flutuante é outro conceito central que prevê as diversas oscilações e profundidades alojadas em locais sujeitos a variações e, portanto, inflexo. É necessário fazer a esponja várias vezes do chão ao céu para descobrir os melhores pontos de vista, as micropaisagens com as perspectivas que as religam e assim poder tentar as escalas táteis e visuais. A pesquisa de arquivo é fundamental para descobrir o sentido profundo do lugar, as lendas, literatura e história. Assim, o oculto resurge, escondido pelo esquecimento da vida cotidiana. Os lugares são ricos de estratos que precisam ser reavaliados através do entrelaçamento de suas respectivas frações (LASSUS, 1995).

Para Ferriolo (2009) as rápidas mudanças contemporâneas, tanto das cidades como das paisagens como um todo impõe um diálogo no sentido do futuro para o passado, e não o inverso. Lassus olha para o futuro para sondar o sentido profundo do espaço e dar-lhe uma função, um significado. Esta dinâmica que se coloca entre os limites de uma paisagem inexistente, desprovida de floresta, cuja ausência se tornou uma metáfora de um mundo conhecido, previsível, faz com que o paisagismo necessite de imaginação para ser capaz de continuar a causar emoções.

Para Lassus essa correlação entre os fenômenos culturais e econômicos mostra que o passado distante de uma cidade pode ser usado para elaborar o seu futuro, e que a missão do paisagista não se limita a propor uma decoração com mais ou menos plantas. Sua missão é entrar no processo de desenvolvimento urbano (PAQUOT, 1998).

\section{O paisagista}

Analisando a obra de Lassus, Ferriolo (2009) concluiu que para esse profissional o paisagista não acumula ações, mas revela as entidades paisagísticas em suas diferentes escalas de identidade reveladas na análise inventiva: destacando-se a estratificação de várias escalas de tempo de várias paisagens que evoluíram ao longo dos anos. Estas condições fazem do jardim um espaço de experiencial tátil onde se descobre o visual: uma arte de exposição imensurável. Entra-se em um contexto entre o tátil e o visual: o local de surgimento do heterogêneo, das contradições e das dissociações, todos colocados nas falhas de uma paisagem mil folhas.

Lassus propõe uma arte da transformação: um processo como um conjunto de movimento interativo de um lugar, sem parar ou congelá-lo, mas escolhendo o caminho. Tudo muda e nada permanece. O paisagismo que é também uma arte da transformação é movimento e caminho. Não é uma prática estática relacionada com os princípios teóricos imutáveis, pois ele é inflexo. Esta é talvez a lição mais clara de Lassus. As idéias caminham com as pernas da humanidade. Sua ação muda ao longo do tempo. A existência de estratégias e soluções é incessante para melhorar o seu local de vida, tanto geral como limitado (FERRIOLO, 2009).

Essa teoria desenvolvida por Lassus e seu grupo de pesquisa, sedimentada durante o periodo de ensino no DEA Jardins Paysages Territoires, esclareceu aos governantes franceses a necessidade de inserir essa dimensão paisagística nos mais variados âmbitos governamentais. A partir desse período se desenvolveu uma legislação paisagística nas várias instancias do poder público, desde o federal até o municipal. Todas essas mudanças ampliaram a atuação do paisagista na França.

Atualmente os paisagistas não são mais apenas arquitetos paisagistas como são tratados pela l'International Federation of Landscape Architects (IFLA), as suas competências se expandiram para novos campos científicos, técnicos e artísticos. Surgiu assim uma categoria mais ampla: os profissionais da paisagem.

Segundo Donadieu (2008) na França os paisagistas podem ser agrupados em categorias de conhecimento e know-how. Em um primeiro grupo que inclui os praticantes e seus teóricos têm-se os técnicos, os engenheiros paisagistas, e os profissionais relacionados com a paisagem (ecologistas, ambientalistas, agrônomos, engenheiros florestais, planejadores, etc.). Num segundo grupo de profissionais da paisagem - paisagistas, podem ser agrupados os cientistas que analisam as regras sociais e legais, além das práticas paisagísticas que utilizam o conceito de paisagem como uma ferramenta para a organização do espaço. O terceiro grupo reúne os especialistas da ciência fundamental que visam desenvolver o conhecimento dos fatos relacionados às paisagens e aos jardins.

A interação desses três grupos de conhecimento, ciência aplicada, prática e fundamental, é frequente, especialmente em projetos interdisciplinares que visam a ação e/ou a renovação do conhecimento. A figura do especialista é compatível com as novas categorias de conhecimento da poisagem, que se distinguem da seguinte forma: conhecimento tecnológico, artes aplicadas e artes plásticas; conhecimento econômico, etnosociologicos, ético e estético; conhecimento biofísico, matemático e histórico-epistemológico (Donadieu 2008).

A política da paisagem desenvolvida na França se estendeu à Europa, e em 20 de outubro de 2000, foi assinada em Florença a Convenção Européia da Paisagem, que suscitou grande interesse entre os países membros do Conselho da Europa. A partir de então se desenvolveu uma política na Europa que não se restringiu às paisagens espetaculares, mas também às pitorescas e banais. Com isso tornou-se necessário considerar essas paisagens em todas as ações de gestão, desde as mais amplas até aquelas mais pontuais, ações essas tanto de organização do território, quanto de planejamento e de desenvolvimento regional, especialmente quando estes têm um impacto sobre a qualidade de vida dos habitantes que estão envolvidos.

\section{A paisagem quotidiana}

Quando se fala em paisagem, logo se pensa nas paisagens notáveis, que fazem parte das identidades nacionais, que muitas vezes foram consagradas pela arte, e que os turistas procuram para viver uma experiência única. Mas é preciso pensar que fora desse contexto do 
espetacular, existem as paisagens do dia a dia, chamadas de coloquial ou quotidiana que desempenham um papel vital no uadro de vida de uma população Esse tipo de paisagem não pode ter o mesmo tipo de tratamento nem a mesma gestão que as paisagens notáveis.

Para Luginbuhl (1995) vários tipos de sensibilidade envolvem a paisagem, estética, afetiva, poética, simbólica, higiênica, ecológica e economica. E será cada um desses tipos de sensibilidade que irá precisar a analise das representações sociais dessas paisagens, que conta com sua dimensão histórica e com seus significados contemporâneos.

As paisagens quotidianas estão impregnadas no inconsciente coletivo e compõem as dimensões psicológicas, socioculturais e afetivas que conjugam com o significado dos lugares. Essas paisagens que num primeiro momento parecem assim tão banais são carregadas de valores e significados para aqueles que a vivem no seu quotidiano. Porém seus valores e significados diferem profundamente dos veiculados pelas paisagens notáveis.

Segundo Bigando (2008) a relação dos habitantes com suas paisagens quotidianas se caracterizam por uma construção do seu dia a dia, o que conduz a uma maior proximidade e subjetividade além de contar com uma apreciação que normalmente não apresenta uma qualificação estética. Nesses casos serão outros valores, ainda mais fortes que os estéticos, que ligam os habitantes aos seus locais onde eles vivem.

A ligação entre os habitantes e seus lugares de vida ultrapassa o quadro de uma relação de simples afeição paisagística para se constituir em um verdadeiro vetor de identidade. As paisagens comuns estão em relação com os habitantes no aqui e agora. É preciso considerar também, que hoje em dia, não é mais conveniente de agir sobre os territórios sem levar em consideração as representações e práticas de seus habitantes, mesmo que suas paisagens possam parecer comuns ou banais. Pois essas práticas e representações além de darem sentido a esses lugares, valorizam também essas paisagens, seja qual for seu grau de banalidade (BIGANDO, 2008).

Entender essa identidade das paisagens comuns é um primeiro passo para um melhor conhecimento desses territórios, sendo um pré requisito para a elaboração e a implantação de todos os projetos de ações ou intervenções sobre esses territórios.

\section{Uma política da paisagem democrática}

Para Ferriolo (2009), uma política democrática da paisagem deve ser direcionada para o conhecimento local e a participação de seus habitantes na escolha dos caminhos que podem melhorar as suas paisagens. A descoberta do lugar está assoiada ao multiculturalismo, ao pertencimento e ao acolhimento. Estes são os passos que levam a condução das paisagens na direção do heterogêneo, com suas contradições e variedades, tornando agradável e acolhedora a vida dos habitantes, tanto no seu entorno imediato como no longinquo. Pensar e agir dessa forma leva a se projetar paisagens agradáveis tanto para a vista como para o espírito. Uma lição deixada por Lassus que não deve ser esquecida, uma nova dimensão para o jardim, um caminho aberto para a paisagem. Lassus mostrou o caminho do paisagista modeno, que levou à descoberta da profundidade do local, e à invenção de uma prática para a paisagem.

Segundo Donadieu e Périgord (2007), o governo Frances experimentou muitos tipos de ações. Nos anos 1970, os especialistas da ciência do meio ambiente criaram o Conservatoire du litorale e a lei de proteção da natureza. Durante os anos 1980, o governo Frances lançou a Mission du paysage, por meio do Ministério do Meio Ambiente, colocando em pratica diferentes experiências de promoção das paisagens ordinárias e cotidianas, onde as coletividades expressavam suas necessidades. Depois da Lei da paisagem de 1983, as ferramentas legais da ação pública da paisagem se modificaram, tais como o selo da paisagem, o suplemento paisagístico da permissão de construções e o suplemento paisagístico da Charte Intercommunale des Parcs Naturels Regionaux. A partir de 1994, foram criados os Contrats de paysage, e em 1995 os Plans de paysage, e de 1996 a 2006 os Atlas des paysages. Com isso, muitos foram os meios colocados à disposição das coletividades públicas para normatizar a produção das paisagens, sejam elas rurais, urbanas e peri - urbanas que englobam o quadro de vida comum, e às vezes também de sítios remarcáveis.

Com a criação da Convenção Européia da Paisagem em 2000, essas ações do governo Frances encontraram um quadro jurídico preciso que permitiu atenuar as insuficiências das leis francesas. Apoiando-se na parte estratégica dessa convenção, a noção de política da paisagem é compreendida como: "a adoção de medidas especiais para a proteção, gestão e organização da paisagem pelas autoridades públicas competentes". Essas medidas podem ser tomadas por ações especificas ou por uma integração sistemática de temas paisagísticos dentro de todas as políticas setoriais.

Aplicada a todo território dos países signatários, a Convenção engloba "espaços naturais, rurais, urbanos e peri urbanos", sejam eles "remarcáveis, comuns ou degradados" (artigo 2)*. Essa convenção reconhece que a qualidade de vida dos europeus se apóia na conscientização dos cidadãos e de seus poderes públicos das possíveis deteriorações de seu quadro de vida, além da alteração resultante do bem estar individual e coletivo. Ao se definir a paisagem, essa convenção retorna ao anseio político de consolidar as identidades sociais e territoriais locais e de basear as da Europa na manutenção e valorização de suas diversidades culturais. A paisagem deveria servir para construir a Europa assim como ela serviu para a construção da identidade nacional suíça (WALTER, 2004).

\section{CONCLUSÕES}

A contribuição dessa visão paisagística desenvolvida por Lassus não visa introduzir uma degradação, mas uma valorização no seu sentido amplo, pois ela insere as necessidades objetivas e subjetivas do seu usuário no conceito da paisagem local, que passa a servir como referencia na concepção dos mais variados projetos.

Essa percepção que teve como origem sua observação da população dos arredores de Paris se desenvolveu a partir dos habitantes paisagistas, que contribuíram com suas metáforas criadas a partir da busca pela beleza em resposta às deficiências que os cercavam. 
Pode-se afirmar que a partir daí, Lassus participou de um grande movimento democrático na França e na Europa para a evolução da paisagem tanto no seu campo de ciências teóricas como aplicadas, contribuindo para com o desenvolvimento da aplicação da dimensão da paisagem, não somente nos jardins, mas nos mais variados campos de intervenção do espaço.

\section{REFERÊNCIAS}

ALVES, S. F. N. S. C.; PAIVA, P. D. O. Os sentidos: jardins e paisagens. Revista Brasileira de Horticultura Ornamental, v.16, n.1, p.47-49, 2010.

BIGANDO E. Le paysage ordinaire, porteur d'une identité habitante. 2008. Disponivel em : http://www. projetsdepaysage.fr/fr/le_paysage_ordinaire_porteur_d une_identite_habitante. Acesso em: 12/04/2013

DONADIEU P. Le paysagiste est-il un expert ? 2008. Disponivel em: http://www.projetsdepaysage.fr/fr/le paysagiste_est_il_un_expert_.Acesso em: 12/04/2013

DONADIEU P., PÉRIGORD M. Le paysage entre nature et cultures. Paris, Ed. Armand Colin, 2007, 127 p.

FERRIOLO, M. V. Bernard Lassus: une pratique démesurable pour le paysage. 2009. Disponivel em: http:// www.projetsdepaysage.fr/fr/bernard_lassus_une_pratique demesurable_pour_le_paysage, acesso em: 15/03/2013.

LASSUS, B.; Berque, A.; Conan, M.; Donadieu, P.; Roger, A.. Mouvance. Cinquante mots pour le paysage. Paris, Éditions de la Villette,1999,100 p.

LASSUS, B. Hypothèses pour une troisième nature. London, Ed. Coracle, 1992, 141p.
LASSUS, B. L'óbligation de l'invention: du paysage aux ambianes successives. In: Roger A.. La théorie du paysage en France (1974-1994). Seyssel, Ed. Champ Vallon, 1995, $464 p$.

LUGINBUHL, Y. Le paysage rural. La couleur de l'agricole, la saveur de l'agricole, mais que reste-t-il de l'agricole? In: Roger A. La théorie du paysage en France (1974-1994). Seyssel, Ed. Champ Vallon, 1995, 464p.

PAQUOT, T. Le paysagiste Bernard Lassus décoré. 2010. Disponivel em: http://www.liberation.fr/ culture/01012305626-le-paysagiste-bernard-lassus-decore, acesso em: 10/03/2013.

PAQUOT, T. Propos recueillis par Thierry Paquot, ̀̀ Paris, le15 octobre 1998. 1998. Disponivel em:

http://www.google.com.br/\#hl=pt-BR\&gs_rn=9\&gs $\mathrm{ri}=\mathrm{psy}-\mathrm{ab} \& \mathrm{pq}=1 \mathrm{e} \% 20$ paysagiste $\% 20$ bernard $\% 20$ lassus $\% 20 \mathrm{~d} \% \mathrm{C} 3 \%$ A 9 cor $\%$ C 3 \% A $9 \& \mathrm{cp}=81 \& \mathrm{gs}$ $\mathrm{id}=6 \& \mathrm{xhr}=\mathrm{t} \& \mathrm{q}=$ Propos $\% 20$ recueillis $\% 20$ par $\% 20$ Thierry $\% 20$ Paquot $\% 2 \mathrm{C} \% 20 \% \mathrm{C} 3 \% \mathrm{~A} 0 \% 20 \mathrm{Paris} \% 2 \mathrm{C} \% 20$ le $15 \% 20$ octobre $\% 201998 . \% 20 \%$ C2\%A9Thierry\%20 Paquot\&es_nrs $=$ true $\& \mathrm{pf}=\mathrm{p} \&$ sclient $=\mathrm{psy}-\mathrm{ab} \& \mathrm{oq}=$ Prop os + recueillis + par + Thierry + Paquot, $+\% \mathrm{C} 3 \% \mathrm{~A} 0+$ Paris, + le $15+$ octobre+1998.+\%C2\%A9Thierry+Paquot\&gs $1=\& p b x=1 \& b a v=$ on.2,or.r_qf. $\& f p=e 1$ feabc 67 fa 8 bac $7 \& b \bar{i}$ $\mathrm{W}=1600 \&$ bih $=750$, acesso em: 10/03/2013.

WALTER F. Les figures paysagères de la nation, territoires et paysages en Europe. $\mathrm{XVI}^{\mathrm{e}}-\mathrm{XX}^{\mathrm{e}}$ siècles. Paris, EHESS, 2004.

ALVES, S. F. N. S. C.; PAIVA, P. D. O. Os sentidos: jardins e paisagens. Revista Brasileira de Horticultura Ornamental, v.16, n.1, p.47-49, 2010. 